\title{
Current psychological therapeutic approaches for gambling disorder with psychiatric comorbidities: A narrative review
}

\author{
Enrique Echeburúa, ${ }^{1}$ Pedro J. Amor, ${ }^{2}$ Montserrat Gómez ${ }^{3}$
}

1 Departamento de Personalidad, Evaluación y Tratamiento Psicológico, Facultad de Psicología, Universidad del País Vasco, San Sebastián, España.

2 Departamento de Psicología de la Personalidad, Evaluación y Tratamiento Psicológicos, Facultad de Psicología, Universidad Nacional de Educación a Distancia (UNED), Madrid, España.

${ }^{3}$ Instituto de formación continua-IL3, Universidad de BarceIona, España. Institut de Diagnòstic Psicològic (sección juego patológico), Tarragona, España.

Correspondence:

Pedro J. Amor

Departamento de Psicología de la

Personalidad, Evaluación y Tratamiento Psicológicos, Facultad de Psicología, Universidad Nacional de Educación a Distancia (UNED). Calle Juan del Rosal 10, 28040, Madrid, España.

Phone: + 34913986 - 517

Email: pjamor@psi.uned.es

Received first version: September 20, 2017

Second version: November 21, 2017 Accepted: November 24, 2017

doi:10.17711/SM.0185-3325.2017.038

\begin{abstract}
Background. Although the presence of a gambling disorder (GD) together with another mental disorder poses special treatment challenges, such as relapses, severe outcomes for patients and families, and increased number of hospitalizations, there are only a few critical reviews in the literature. Objective. To review empirical evidence of psychological approaches to cope specifically with these dual disorders. Method. A narrative review of the relevant bibliography on this topic was carried out. A systematic search of original articles (2010-October 2017) was conducted in MEDLINE and Psyclnfo. Key terms were: 1. gambling/gamblers, 2. treatment/intervention/therapy/therapeutics, and 3. dual diagnosis/comorbidity. Results. Current treatment for GD involves a number of different options, including inpatient treatments, intensive outpatient therapy, individual and group cognitive-behavioral options (CBT), self-help groups, and pharmacotherapy. Inpatient care is generally limited to patients with severe acute crises, treatment failures, and severe comorbid disorders, particularly depression and attempted suicide. Treatment for GD with other mental disorder needs more research. CBT, motivational enhancement therapy and self-help groups have some empirical support when GD is comorbid with other addiction, mood disorder, or schizophrenia. Programs that combine pharmacotherapy and psychosocial treatments for GD into a single comprehensive package are most likely to have good treatment outcomes, at least with regard to treatment retention. Discussion and conclusion. Interventions should be tailored to the needs of the patients. Future research should be concerned about the statistical power of the studies, implement motivational strategies for patients with poor medication adherence, and design measures to study treatment fidelity in the CBT groups.
\end{abstract}

Keywords: Gambling disorder, comorbidity, therapeutics, psychological treatment.

\section{RESUMEN}

Antecedentes. La presencia comórbida del juego patológico (JP) con otro trastorno mental plantea diversos desafíos al tratamiento, como las recaídas, las repercusiones negativas para los pacientes y sus familias y un mayor número de hospitalizaciones. Objetivo. Revisar la evidencia empírica existente sobre el papel que cumplen las terapias psicológicas en el tratamiento de estos trastornos duales. Método. Se realizó una revisión narrativa de la bibliografía relevante sobre este tema. Se llevó a cabo una búsqueda sistemática de artículos originales (2010-octubre 2017) en MEDLINE y PsycInfo con las palabras clave: 1. gambling or gamblers, 2. Treatment, intervention, therapy or therapeutics, y 3. dual diagnosis or comorbidity. Resultados. Hay diversas terapias para el JP: tratamiento hospitalario, terapia intensiva ambulatoria, terapia cognitivo-conductual (TCC) individual y en grupo, Jugadores Anónimos y farmacoterapia. La hospitalización se limita a los pacientes con una crisis aguda, fracasos terapéuticos previos y trastornos comórbidos graves, como la depresión y los intentos de suicidio. El tratamiento para el JP comórbido con otro trastorno (depresión, abuso de sustancias o esquizofrenia) requiere más investigación. Las terapias más efectivas en estos casos son al parecer la TCC, la entrevista motivacional y los grupos de autoayuda. Los programas que combinan farmacoterapia con tratamientos psicológicos parecen aumentar la retención del tratamiento. Discusión y conclusión. La intervención debe adaptarse a las necesidades específicas de cada paciente y la investigación debe mejorar las estrategias motivacionales cuando los pacientes muestran una deficiente adherencia a la medicación, así como diseñar medidas para mejorar la fidelidad al tratamiento psicológico.

Palabras clave: Juego patológico, comorbilidad, terapia, tratamiento psicológico. 


\section{BACKGROUND}

Gambling disorder (GD) is a relatively common and often disabling psychiatric condition characterized by intrusive urges to engage in deleterious gambling behavior in terms of time invested and money wagered, which results in significantly negative effects on gamblers daily lives and quality of life. DSM-5 criteria for gambling disorder focus on preoccupation with gambling, need to gamble increasing amounts of money, and repeated unsuccessful efforts to control gambling. Furthermore, relapse following the treatment is a common outcome (González-Ortega, Echeburúa, Corral, Polo-López, \& Alberich, 2013; Kassani, Niazi, Hassanzadeh, \& Menati, 2015).

The occurrence of GD varies from country to country and the measures for calculating the prevalence are not always the same. In general, about $.8 \%-1.5 \%$ of the adult population can be classified as probable individuals with GD while the prevalence of problem gambling is $2.5 \%$ (Kessler et al., 2008). Substance abusers and patients seeking treatment for psychological problems (e. g., anxiety and mood disorders) tend to have high rates of gambling problems $(20 \%)$. In turn, individuals with GD often suffer from comorbid disorders, such as personality disorders $(47.9 \%)$, mood disorders $(23.1 \%)$, alcohol use disorders $(21.2 \%)$, or anxiety disorders (17.6\%) (Dowling et al., 2015).

Patients with dual disorders are highly prone to adverse outcomes in several domains (about 60\%): increased rates of hospitalization, nonadherence to treatment and poor overall response to pharmacologic treatment (Green, Drake, Brunette, \& Noordsy, 2007). Comorbid mental disorders are often undetected in individuals with GD, which can complicate their treatment (Ziedonis, Steinberg, Smelson, \& Wyatt, 2009). The presence of GD and another mental disorder poses special diagnostic and treatment challenges. Thus, the personal, family and social problems of these patients increase and reduce gains of the treatment; patients may relapse or give up the therapy. Therefore, there is a need for comprehensive assessment and integrated intervention that addresses the multiple problems associated with these co-occurring disorders.

There are several reviews about the psychological treatment of GD in the literature, but there is only one mini-review about GD with different kinds of psychiatric comorbidities and with the main focus on drug treatment (Dowling, Merkouris, \& Lorains, 2016). Therefore, the main aim of this research is to review existing evidence on the role of evidence-based psychological interventions for disordered gamblers with different co-occurring psychiatric disorders.

\section{METHOD}

A systematic search of original articles (2010-October 2017) was conducted in MEDLINE and PsycInfo. Key terms in title, abstract and keywords were: 1. gambling or gamblers, 2. treatment, intervention, therapy, or therapeutics, and 3. dual diagnosis or comorbidity. Four hundred and eight references were found. Regarding exclusion and inclusion criteria for the searched records, case studies, dissertations, letters to the editor, and duplicate records were removed from the analysis. Finally, empirical articles and other relevant documents in this topic dealing with adult patients were taken into account (meta-analysis research or reviews). The analytic plan is based on the search of relevant publications for this topic, the selection, reading, synthesis, and exposition of the state of the art.

\section{RESULTS}

\section{Psychological intervention for gambling disorder}

Treatments for GD reported in the literature are quite similar to methods to treat other addictions. However, few empirically supported treatments for GD have been developed. Regarding treatment goals, complete abstinence versus moderated gambling is an issue that needs to be addressed. Both goals are necessary for different kinds of patients (Echeburúa \& Fernández-Montalvo, 2005). While abstinent focused treatment programs are the best option for strictly individuals with GD, moderated gambling in a harm reduction approach may be interesting for problem gamblers.

Current treatment for GD involves a number of different options, including inpatient treatments, intensive outpatient, individual and group cognitive-behavioral options (CBT), and pharmacotherapy. Inpatient care is generally limited to patients with severe acute crises, treatment failures, and severe comorbid disorders, particularly depression and attempted suicide (Echeburúa, 2015).

\section{Behavioral and cognitive-behavioral approaches}

Behavioral approach takes into account three components of gambling behavior: antecedents (financial pressure, gambling cues, positive or negative emotions, interpersonal factors, urges to gamble), overt or covert behavior itself (coping strategies to deal with negative feelings, thinking about gambling), and consequences (autonomic arousal, opportunities to socialize, escape from personal problems, monetary gain to cope with financial loss) (Hodgins \& Holub, 2007).

Behavioral therapy considers disordered gambling a learned behavior and relies on techniques such as stimulus control, systematic exposure, and skills development to reverse the learned behavior and the association between arousal and conditioned elicitors. Reduction in gambling is expected if patients can successfully develop and use alternative coping responses to deal with urges to gamble (Echeburúa, 2015). 
Stimulus control involves limiting access to money, not visiting venues that offer gambling, and not spending time with people associated with heavy gambling. As treatment advances, the control of stimuli is fades gradually, except avoiding gambling friends. Recovering gamblers are also encouraged to meet with a financial planner, to cancel all credit cards, and to turn over control of money to another person. Self-exclusion from gambling venues can be an adjunct to treatment (Nelson, Kleschinsky, LaBrie, Kaplan, \& Shaffer, 2010).

Exposure with response prevention is focused on making patients experience the desire to gamble and teach them how to resist it in a gradually more self-controlled way. The aim of systematic exposure to cues and situations of risk is to make the cues lose their power to induce urges and gambling behavior. If responses are prevented or controlled, the stimulus-response relationship will weaken. In addition, patients are taught alternative strategies to cope with their increased anxiety. This type of therapy is designed to deal with cravings and urges for gambling by increasing confidence in the ability for self-control (Echeburúa, Báez, \& Fernández-Montalvo, 1996). According to the meta-analysis of Pallesen, Mitsem, Kvale, Johnsen, and Molde (2005), interventions involving developing relaxation skills, exposure to gambling cues, and direct behavioral action are effective in improving gambling urges, time and money spent, and abstinence. In addition, behavioral change is related to cognitive change after treatment.

Cognitive therapy aims to help patients challenge and overcome irrational thoughts that are believed to initiate and maintain the undesirable behavior. Patients are taught to be aware of the link among thoughts, behavior, and emotion. Many patients do not understand the concepts of probability and randomness, believing that they can exert some control over whether they win or lose. Treatment typically involves teaching patients strategies to correct their erroneous thinking by providing corrective information through education, logical discussion, or behavioral experimentation. If the erroneous perceptions and understanding of randomness in the gambler can be corrected, then the motivation to gamble should decrease dramatically. Cognitive therapy also aids gamblers in coping with urges to gamble, managing negative emotions and training in problem solving techniques (Ladouceur et al., 2001).

The more recent randomized clinical trials have focused on combined cognitive and behavioral approaches (CBT) (cognitive correction, problem solving training, and social skills training) (Jiménez-Murcia et al., 2012; Petry $\&$ Roll, 2006). Both individual and group CBT appear effective for reducing gambling. Anyway, more randomized clinical trials with bigger samples are needed to confirm the effectiveness of CBT for problem gambling (Smith, Dunn, Harvey, Battersby, \& Pols, 2013).

\section{Motivational enhancement therapy}

Another approach adopted to help problem gamblers focuses on the use of short-term brief motivational enhancement therapy (MET) and telephone counseling, mailed self-help workbooks, and online resources. Brief treatment is defined as that using less professional resources or time (four or fewer sessions and sometimes one single session) than usual face-to-face interventions (typically, six to twelve sessions of therapist contact). This therapeutic modality may be an important innovation to helping people with gambling problems who fail or refuse to seek treatment in traditional therapeutic settings and may enhance patients' sense of control over their own recovery. Motivational interviewing (MI) is often a 50-minute face-to-face or telephone session that addresses the principles of MI used to build commitment to change (Yakovenko, Quigley, Hemmelgarn, Hodgins, \& Ronksley, 2015).

The MI focuses on patient's intrinsic motivation for change and on patient's strengths to enhance self-efficacy. This approach has proven to be effective in the short term, at least with those with less severe gambling problems (Diskin \& Hodgins 2009; Hodgins, Currie, Currie, \& Fick, 2009; Yakovenko et al., 2015).

A combined motivational interviewing and CBT program applied in group or individual format, or even adapted to a web-based format (Carlbring \& Smit, 2008), can improve GD behaviors, as well as gambling correlates. Moreover the addition of motivational interviewing to CBT can reduce treatment attrition and improve outcomes (Wulfert, Blanchard, Freidenberg, \& Martell, 2006).

However, these motivational approaches, which are more attractive to gamblers and may result in an increase of treatment seekers, cannot be so effective with severe individuals with GD or patients with comorbid pathology. Further research is required to determine the effects of MI treatment over time and the efficacy of these programs when compared to more established CBT. Besides, the efficacy may vary based on target population (severity of pathological gambling, presence of comorbidity, etc.) and on the follow-up period after the intervention (Yakovenko et al., 2015).

\section{Self-help groups}

Gamblers Anonymous (GA) is the primary self-help group focused on an abstinence-based treatment program. GD is conceptualized as an illness which can be arrested but never cured, so people affected by this problem have a permanent predisposition for losing control over their gambling.

The therapeutic rationale for GA is that the 12-steps to recovery will lead gamblers to attain abstinence. The group format is intended to provide a sense of common purpose and understanding, emotional and spiritual support, and hope. Anonymity allows for members to feel safe in sharing openly with other members (Hodgins \& Holub, 2007). 
The efficacy of GA has not been demonstrated in controlled studies. Relapse rates tend to be quite high. Attrition rate is also high. In some studies people attending GA have better gambling outcomes than those who do not, even though they are engaged in professional treatment concurrently (Petry \& Roll, 2006).

The therapeutic effectiveness of GA has also been explored with respect to participation by the gambler's partner. There is a trend for higher abstinence rates for gamblers whose partners are present at meetings compared with gamblers whose partners do not attend.

There is a particular need for studies of the role of GA in recovery and treatment outcomes. A recent study found that there were not any differences on key gambling variables (e. g., frequency, abstinence rates, money wagered) at 12 months between a program of CBT and 12-step therapy (Toneatto \& Dragonetti, 2008).

\section{Treating comorbid gambling disorder and severe mental disorders}

\section{Treatment of gambling disorder with affective and addictive mental disorders}

There are several studies on the efficacy of treatments when there is dual disorders, especially between GD and mood disorders or alcohol/substance abuse. Psychological treatments effective in treating comorbidity between GD and depression are CBT and imaginal desensitisation plus motivation interviewing (Dowling et al., 2016).

Pharmacological treatments, such as opioid antagonists (Grant, Kim, Hollander, \& Potenza, 2008), memantine, that was associated with diminished gambling and improved cognitive flexibility (Grant, Chamberlain, Odlaug, Potenza, \& Kim, 2010), citalopram (Zimmerman, Breen, \& Posternak, 2002), and sustained-release lithium for bipolar spectrum disorders (Chaim, Nazar, Hollander, \& Lessa, 2014; Hollander, Pallanti, Allen, Sood, \& Rossi, 2005) may reinforce psychological therapy.

On the other hand, psychological approaches may be effective in treating comorbidity between GD and alcohol/ substance abuse: CBT, motivation interviewing, Internet delivered self-help CBT, 12-step therapy, solution-focused therapy, and dialectical behavior therapy (Dowling et al., 2016). In this therapeutic context, there are also positive results combining different approaches, such as MET + CBT (Petry, Rash, \& Alessi, 2016).

\section{Treatment of gambling disorder with schizophrenia}

There are higher rates of pathological gambling in schizophrenic populations (between $4.7 \%$ and $10 \%$ ) than in the non-schizophrenic population (1-5\%) (Dowling et al., 2015; Haydock, Cowlishaw, Harvey, \& Castle, 2015). These patients also have greater alcohol use severity, higher depression scores, and more outpatient mental health care utilization.
Apart from three case reports (Borras \& Huguelet, 2007; Potenza \& Chambers, 2001; Shonin, VanGordon, \& Griffiths, 2014), there is only one controlled trial that tested the clinical effectiveness of a cognitive-behavioral program specifically adapted for individuals with GD with chronic schizophrenia, with post-treatment and 3,6, and 12-month follow-up assessments. Adaptation of CBT for these individuals dually diagnosed with GD and chronic schizophrenia took into account several aspects: The active role of the therapist to help patients fulfil the self-reports; the presence of a co-therapist (a family or staff member) in order to enhance motivation for treatment, to encourage patients to carry out in vivo exposure tasks and to check information provided by patients; and the implementation of the program in the stabilization phases of the schizophrenia. This modified CBT (stimulus control and gradual in vivo exposure with response prevention) has proven to be an evidence-based psychosocial intervention for patients with these dual disorders (Echeburúa, Gómez, \& Freixa, 2011).

In this study, individuals dually diagnosed with GD and chronic schizophrenia have benefited from medication and supportive psychological treatment to cope with GD. Thus, the improvement rate in the experimental group was $73.9 \%$ (with all patients being treatment completers), versus 19\% in the control group at the 3-month follow-up.

Predicting relapse in GD in individuals with chronic schizophrenia after treatment can be useful in targeting patients for aftercare services. The therapeutic failure rate was $43 \%$ and it was associated to the age of first episode of schizophrenia, the number of episodes, and the age of onset in gambling behavior (Echeburúa, Gómez, \& Freixa, 2017).

\section{Future challenges}

Only a small proportion of the patients who are suffering from GD (about 6\%) seek formal treatment. Natural recovery from problem gambling can occur in about $35 \%$, but most individuals with GD report a chronic course, with symptom severity fluctuating over time (Grant \& Odlaug, 2012).

For individuals with GD, treatment compliance is an issue because they are often ambivalent about giving up their gambling and altering ineffective long-standing patterns of coping. Some people do not seek treatment, some drop out after one or two sessions and some can decide to terminate treatment only after a few weeks. Motivational enhancement therapy, behavior contracts and flexible treatment goals might improve treatment compliance.

Interventions should be tailored to the needs of the patients. Substantial progress has been made in understanding the treatment of this disorder, but there is not yet research basis for matching patients to treatments according to different characteristics (e. g., subtypes of gamblers, different type of gambling or comorbid disorders). Table 1 shows 
Table 1

Variables to be considered when planning treatment

\begin{tabular}{ll}
\hline Individuals with GD & Treatment \\
\hline Homogeneous & Manualized \\
& MI + CBT (exposure with response prevention + relapse prevention) \\
Individual / group therapy \\
Heterogeneous & Tailored \\
& Subtypes of individuals with GD: \\
& Behaviorally conditioned problem gamblers, emotionally vulnerable or antisocial (Milosevic \& Led- \\
& gerwood, 2010) \\
& Impulsive, obsessive-compulsive, addictive (lancu, Lowengrub, Dembinsky, Kotler, \& Dannon, 2008) \\
& Personalized treatment program according to the: \\
& Degree of awareness of the problem and readiness for change \\
& Pathological game: Severity of the problem, loss of control, craving, time spent playing, expenditure. \\
& Comorbidity (personality, anxiety, mental disorders, alcohol/substance abuse, etc.) \\
& Psychosocial consequences and degree of interference caused by the game and the other comor- \\
bid disorders (couple, family, friends, workplace, gambling debts, financial or legal problems...) \\
Sociodemographic characteristics (age, gender, degree of family and social support, etc.)
\end{tabular}

Note: $\mathrm{GD}$ = Gambling Disorder; $\mathrm{MI}$ = Motivational Interviewing; CBT = Cognitive Behavioral Therapy.

some variables that could be considered in order to plan the treatment in an individualized way.

In conclusion, a combination of individual, family and group therapy may be the best option, although individualization should be emphasized. Medication (e. g., ISSRs) may be needed to treat associated anxiety or depression. Anyway, our understanding of Internet gambling is still quite limited. There is no evidence-based research for treatment options regarding this topic.

\section{DISCUSSION AND CONCLUSION}

Both individual and group CBT appear to be effective in the treatment of GD and its correlates (Gooding \& Tarrier, 2009). Group therapy is not only just cost effective; it also enables gamblers to learn from and support each other. Individual therapy may be more suitable for those who prefer discussing life events on a one-to-one basis (Oei, Raylu, \& Casey, 2010).

Virtual counseling (Internet or computerized therapy) is another treatment option for individuals with GD who may be reluctant to enter individual or group therapy.

Gambling studies should focus particularly on treatments that have manual-guided treatments. Poor specification of the therapeutic methods used hinders the replication of successful programs. Not only do therapist's manuals guide interventions, but they also facilitate the clarification of the specific contribution of particular treatment components.

Gambling behavior should be routinely investigated as part of all psychiatric assessments. Taking note of behaviors consistent with GD in individuals with severe mental disorders -for example, frequent missed appointments, poor medication adherence, and financial or legal problems- may be very helpful. Honest reporting of actual gambling is most likely to occur if the clinician establishes a nonjudgmental therapeutic alliance when assessing a patient who may have a co-occurring addiction (Green et al., 2007).

Pharmacotherapy is not the primary treatment for GD; however, patients with dysphoria should be evaluated for antidepressant medication. Family therapy may be indicated in the presence of extreme family estrangement; and substance abuse counseling may be necessary for those whose addictive behavior also includes alcohol or other drug abuse. Inpatient programs for individuals with severe gambling disorder, with comorbid disorders or attempted suicide (or suicidal ideation), may be also useful (Grant \& Odlaug, 2012).

There is growing evidence for the effectiveness of psychosocial interventions, such as motivational interviewing (short in duration, easy to be administered, and cost-effective) and cognitive-behavioral therapy to cope with specific needs of people with dual disorders (Yakovenko et al., 2015). However, there are serious implementation barriers related to service organization, training and the difficulties of engaging people with a severe mental disorder in treatment (Abou-Saleh, 2004).

Programs that combine pharmacotherapy and psychosocial treatments for GD into a single comprehensive package are most likely to have good treatment outcomes, at least with regard to treatment retention.

Finally, since the population of mentally ill individuals with GD is heterogeneous, it would be interesting to evaluate a patient-treatment matching strategy intended for these dual-diagnosed patients (Chen, Barnett, Sempel, \& Timko, 2006).

\section{Funding}

None. 


\section{Conflicts of interest}

The authors declare they have no conflicts of interest.

\section{REFERENCES}

Abou-Saleh, M. T. (2004). Dual diagnosis: management within a psychosocial context. Advances in Psychiatric Treatment, 10(5), 352-360. doi: 10.1192/ apt.10.5.352

Borras, L., \& Huguelet, P. (2007). Schizophrenia and pathological gambling. The American Journal on Addictions, 16(4), 269-271. doi:10.1080/10550490701389765

Carlbring, P., \& Smit, F. (2008). Randomized trial of internet-delivered self-help with telephone support for pathological gamblers. Journal of Consulting and Clinical Psychology, 76(6), 1090-1094. doi:10.1037/a0013603

Chaim, C. H., Nazar, B. P., Hollander, E., \& Lessa, J. M. (2014). Pathological gambling treated with lithium: The role of assessing temperament. Addictive Behaviors, 39(12), 1911-1913. doi: 10.1016/j.addbeh.2014.05.016

Chen, S., Barnett, P. G., Sempel, J. M., \& Timko, C. (2006). Outcomes and costs of matching the intensity of dual-diagnosis treatment to patients' symptom severity. Journal of Substance Abuse Treatment, 31(1), 95-105. doi: 10.1016/j. jsat.2006.03.015

Diskin, K. M., \& Hodgins, D. C. (2009). A randomized controlled trial of a single session motivational intervention for concerned gamblers. Behaviour Research and Therapy, 47(5), 382-388. doi: 10.1016/j.brat.2009.01.018

Dowling, N. A., Cowlishaw, S., Jackson, A. C., Merkouris, S. S., Francis, K. L., \& Christensen, D. R. (2015). Prevalence of psychiatric co-morbidity in treatment-seeking problem gamblers: A systematic review and meta-analysis. Australian and New Zealand Journal of Psychiatry, 49(6), 519-539. doi: 10.1177/0004867415575774

Dowling, N. A., Merkouris, S. S., \& Lorains, F. K. (2016). Interventions for comorbid problem gambling and psychiatric disorders: Advancing a developing field of research. Addictive Behaviors, 58, 21-30. doi: 10.1016/j.addbeh.2016.02.012

Echeburúa, E., Báez, C., \& Fernández-Montalvo, J. (1996). Comparative effectiveness of three therapeutic modalities in the psychological treatment of pathological gambling: Long-term outcome. Behavioural and Cognitive Psychotherapy, 24(1), 51-72. doi: 10.1017/S1352465800016830

Echeburúa, E., \& Fernández-Montalvo, J. (2005). Psychological Treatment of Slot-Machine Pathological Gambling: New Perspectives. Journal of Gambling Studies, 21(1), 21-26. doi: 10.1007/s10899-004-1918-6

Echeburúa, E., Gómez, M., \& Freixa, M. (2011). Cognitive-behavioural treatment of pathological gambling in individuals with chronic schizophrenia: A pilot study. Behaviour Research and Therapy, 49(11), 808-814. doi: 10.1016/j. brat.2011.08.009

Echeburúa, E. (2015). Clinical management of gambling disorder. In N. Guebaly, G. Carra, \& M. Galanter (Eds.), Textbook of Addiction Treatment: International Perspective (vol. 3, pp. 1475-1490). Milan: Springer.

Echeburúa, E., Gómez, M., \& Freixa, M. (2017). Prediction of relapse after cognitive-behavioral treatment of gambling disorder in individuals with chronic schizophrenia: A survival analysis. Behavior Therapy, 48(1), 69-75. doi: 10.1016/j.beth.2016.09.008

González-Ortega, I., Echeburúa, E., Corral, P., Polo-López, R., \& Alberich, S. (2013). Predictors of pathological gambling severity taking gender differences into account. European Addiction Research, 19(3), 146-154. doi: 10.1159/000342311

Gooding, P., \& Tarrier, N. (2009). A systematic review and meta-analysis of cognitive-behavioural interventions to reduce problem gambling: Hedging our bets?. Behaviour Research and Therapy, 47(7), 592-607. doi: 10.1016/j. brat.2009.04.002

Grant, J. E., Kim, S. W., Hollander, E., \& Potenza, M. N. (2008). Predicting response to opiate antagonists and placebo in the treatment of pathological gambling. Psychopharmacology, 200(4), 521-527. doi: 10.1007/s00213-008-1235-3

Grant, J. E., Chamberlain, S. R., Odlaug, B. L., Potenza, M. N., \& Kim, S. W. (2010). Memantine shows promise in reducing gambling severity and cognitive inflexibility in pathological gambling: A pilot study. Psychopharmacology, 212(4), 603-612. doi: 10.1007/s00213-010-1994-5
Grant, J. E., \& Odlaug, B. L. (2012). Psychosocial interventions for gambling disorders. In Increasing the odds. What Clinicians Need to Know About Gambling Disorders (vol. 7, pp. 38-51). Washington, DC: National Center for Responsible Gaming.

Green, A. I., Drake, R. E., Brunette, M. F., \& Noordsy, D. L. (2007). Schizophrenia and co-occurring substance use disorder. The American Journal of Psychiatry, 164(3), 402-408.

Haydock, M., Cowlishaw, S., Harvey, C., \& Castle, D. (2015). Prevalence and correlates of problem gambling in people with psychotic disorders. Comprehensive Psychiatry, 58, 122-129. doi: 10.1016/j.comppsych.2015.01.003

Hodgins, D. C., \& Holub, A. (2007). Treatment of Problem Gambling. In G. Smith, D. C. Hodgins, \& R. J. Williams (Eds.), Research and Measurement Issues in Gambling Studies (pp. 372-397). Amsterdam: Elsevier.

Hodgins, D. C., Currie, S. R., Currie, G., \&, Fick, G. H. (2009). Randomized trial of brief motivational treatments for pathological gamblers: More is not necessarily better. Journal of Consulting and Clinical Psychology, 77(5), 950-960. doi: 10.1037/a0016318

Hollander, E., Pallanti, S., Allen, A., Sood, E., \& Rossi, N. B. (2005). Does sustained-release lithium reduce impulsive gambling and affective instability versus placebo in pathological gamblers with bipolar spectrum disorders? The American Journal of Psychiatry, 162(1), 137-145. doi: 10.1176/appi.ajp.162.1.137

Jiménez-Murcia, S., Bove, F. I., 1srael, M., Steiger, H., Fernández-Aranda, F., Álvarez-Moya, E., ... \& Menchón, J. M. (2012). Cognitive-behavioral therapy for pathological gambling in Parkinson's disease: A pilot controlled study. European Addiction Research, 18(6), 265-274. doi: 10.1159/000337442

Kassani, A., Niazi, M., Hassanzadeh, J., \& Menati, R. (2015). Survival analysis of drug abuse relapse in addiction treatment centers. International Journal of High Risk Behaviors and Addiction, 4(3), e23402. doi: 10.5812/ijhrba.23402

Kessler, R. C., Hwang, I., LaBrie, R., Petukhova, M., Sampson, N. A., Winters, K. C., \& Schaffer, H. J. (2008). DSM-IV pathological gambling in the National Comorbidity Survey Replication. Psychological Medicine, 38(9), 1351-1360. doi: $10.1017 / \mathrm{S} 0033291708002900$

Ladouceur, R., Sylvain, C., Boutin, C., Lachance, S., Doucet, C., Leblond, J., \& Jacques, C. (2001). Cognitive treatment of pathological gambling. Journal of Nervous and Mental Disease, 189(11), 774-780.

Nelson, S. E., Kleschinsky, J. H., LaBrie, R. A., Kaplan, S., \& Shaffer, H. J. (2010). One decade of self-exclusion: Missouri casino self-excluders four to ten years after enrollment. Journal of Gambling Studies, 26(1), 129-144. doi: 10.1007/ s10899-009-9157-5

Oei, T. S., Raylu, N., \& Casey, L. M. (2010). Effectiveness of group and individual formats of a combined motivational interviewing and cognitive behavioral treatment program for problem gambling: A randomized controlled trial. Behavioural and Cognitive Psychotherapy, 38(2), 233-238. doi: 10.1017/ S1352465809990701

Pallesen, S., Mitsem, M., Kvale, G., Johnsen, B., \& Molde, H. (2005). Outcome of psychological treatments of pathological gambling: A review and meta-analysis. Addiction, 100(10), 1412-1422. doi: 10.1111/j.1360-0443.2005.01204.x

Petry, N. M., \& Roll, J. M. (2006). Cognitive-Behavioral Treatments for Pathological Gambling. In P. Ghezzi, C. A. Lyons, M. R. Dixon, G. R. Wilson, P. Ghezzi, C. A. Lyons, ... \& G. R. Wilson (Eds.), Gambling: Behavior theory, research, and application (pp. 249-260). Reno, NV: Context Press.

Petry, N. M., Rash, C. J., \& Alessi, S. M. (2016). A randomized controlled trial of brief interventions for problem gambling in substance abuse treatment patients. Journal of Consulting and Clinical Psychology, 84(10), 874-886. doi: 10.1037/ ccp0000127

Potenza, M. N., \& Chambers, R. A. (2001). Schizophrenia and pathological gambling. The American Journal of Psychiatry, 158(3), 497-498. doi: 10.1176/appi. ajp.158.3.497-a

Shonin, E., VanGordon, W., \& Griffiths, M. D. (2014). Cognitive behavioral therapy (CBT) and Meditation Awareness Training (MAT) for the treatment of co-occurring schizophrenia and pathological gambling: A case study. International Journal of Mental Health and Addiction, 12(2), 181-196. doi: 10.1007/s11469013-9460-3

Smith, D. P., Dunn, K. I., Harvey, P. W., Battersby, M. W., \& Pols, R. G. (2013). Assessing randomised clinical trials of cognitive and exposure therapies for 
gambling disorders: A systematic review. Behaviour Change, 30(3), 139-158. doi: $10.1017 /$ bec. 2013.15

Toneatto, T., \& Dragonetti, R. (2008). Effectiveness of community-based treatment for problem gambling: A quasi-experimental evaluation of cognitive-behavioral vs. twelve-step therapy. The American Journal on Addictions, 17(4), 298-303. doi: 10.1080/10550490802138830

Wulfert, E., Blanchard, E. B., Freidenberg, B. M., \& Martell, R. S. (2006). Retaining pathological gamblers in cognitive behavior therapy through motivational enhancement: A pilot study. Behavior Modification, 30(3), 315-340.

Yakovenko, I., Quigley, L., Hemmelgarn, B. R., Hodgins, D. C., \& Ronksley, P. (2015). The efficacy of motivational interviewing for disordered gambling:
Systematic review and meta-analysis. Addictive Behaviors, 43, 72-82. doi: 10.1016/j.addbeh.2014.12.011

Ziedonis, D. M., Steinberg, M., Smelson, D. A., \& Wyatt, S. A. (2009). Co-occurring addiction and psychotic disorders. In R. Ries, D. Fiellin, S. Miller, \& R. Saitz (Eds.), Principles of addiction medicine (4th ed., pp. 1193-1209). New York: American Society of Addiction Medicine.

Zimmerman, M., Breen, R. B., \& Posternak, M. A. (2002). An open-label study of citalopram in the treatment of pathological gambling. The Journal of Clinical Psychiatry, 63(1), 44-48. 